\title{
Information Technology as a Factor of Sustainable Development of Serbian Agriculture
}

\author{
Žana Jurjević \\ Faculty of Economics in Subotica, University of Novi Sad, Serbia \\ Ivan Bogićević \\ Societe Generale Serbia, Serbia \\ Danilo Đokić \\ Faculty of Economics in Subotica, University of Novi Sad, Serbia \\ Bojan Matkovski \\ Faculty of Economics in Subotica, University of Novi Sad, Serbia
}

\begin{abstract}
Trend of population growth and the need for greater production of health-safe food, on the one hand, and environmental protection on the other hand, affect the change of production technologies in agriculture. Challenges of modern agriculture are reflected in the growth of productivity, but also the long-term sustainability of the agricultural sector. It is indisputable that information technology (IT) has a direct impact on the productivity of agriculture, and as the ultimate goal leads to the growth of the profit of agricultural producers. Precise agriculture, the application of state-of-the-art technical systems for satellite guidance and automatic management, as well as the use of Geographic Information Systems (GIS) lead to yield growth, but also affect the rational use of inputs, which leads to reduction of adverse effects on the environment. Accordingly, the implementation of new technologies in agriculture is an important factor in improving agricultural production, as well as the potential for sustainable development of this sector. The units of observation in this research are Serbia and all countries of the European Union. The aim of this research is to determine the position of Serbia in relation to the countries of the European Union in terms of the dimensions of sustainable development of agriculture, as well as to consider the current level of application of information technologies in the agriculture of these countries. The paper analyzes a set of indicators of economic, ecological and social sustainability and their connection with the implementation of information technologies in agriculture. The results of the research indicate that the current application of information technologies in Serbia's agriculture, compared to EU countries, is modest, primarily due to the unfavorable educational structure of agricultural producers, as well as limited financial resources, which significantly impedes the process of IT implementation.
\end{abstract}

Keywords

Information Technology, Agriculture, Serbia.

\section{Introduction}

The challenges of today's business dictate certain changes. In agriculture, globally, the trend of population growth, the impact of agriculture on the environment, the reduction of greenhouse gases, and the increase in productivity and the efficiency of agriculture, affect changes in production technologies. The ultimate goal of new technologies is reflected in the long-term sustainability of agriculture. In other words, in addition to the economic effects (profit growth, productivity, etc.), new technologies will be environmentally friendly and socially acceptable. Within this research, the focus is on Information Technology (IT) in agriculture. The term IT includes a number of technologies related to information processing and communication 
assistance. According to Franklyn \& Tukur (2012) there are several reasons for the successful adoption of IT in agriculture: an increased need for information; the widespread availability of computers and the Internet and the ease use of software packages; maintaining existing competencies; flexibility; timely information and management support. In addition, IT in agriculture also affects the competitiveness of agricultural producers through: finding new customers; the use of market information for optimum sales, but also the procurement of inputs; introduction of quality standards; better production management and data analysis for more efficient planning of future business processes (FACET, 2013). According to Ćelić, Drašković, Uzelac \& Petrov (2018) the most influential trend, which has emerged as a result of the development of information and communication technologies, is business over the internet.

The challenge is to ensure that new technologies help farmers become more economically competitive, and that these technologies are environmentally sustainable. New trends impose increasing attention to the conservation of natural habitats, with the control of the consumption of natural resources. Such trends also occur in the context of agricultural production. Namely, sustainable agriculture is defined as a part of overall sustainable development at the United Nations Conference on Sustainable Environment and Development in 1992, in the Agenda 21 document (UNCED, 1992). Sustainability in agriculture is established as a link between the ecological production method and the agricultural production itself. The concept of sustainable agriculture was created in response to the increasing exploitation of agricultural resources due to conventional agricultural production, which led to certain ecological consequences (Tilman et al., 2001). This concept implies economic, environmental and social sustainability of a sector. The development of agriculture in the last decade had the greatest merit due to large research in the field of information technology, characterized by high productivity and an intensive method of production (Verdouw, Beulens, Trienekens, \& Verwaart, 2010). As a result of research in the application of information technologies in the field of agricultural production, ERP systems, IT applications, Global Positioning System, Geographic Information System (GIS) and remote detection have been developed. Agricultural producers, especially in developed countries, strive to implement new technologies, or to establish the concept of precise agriculture in order to achieve the sustainability of this sector. The concept of precise agriculture implies the optimal use of agricultural inputs, that is, pesticides, chemical fertilizers, water use and efficient use of irrigation systems, as well as waste management in agriculture (Legg \& Viatte, 2001).

Big farms, which are market-oriented, legal entities and entrepreneurs, are investing heavily in new technologies, as it is necessary to respond in an appropriate manner to rapid changes in terms of market liberalization and the increase of foreign competition. The problem is small family farms, with traditional production technologies. In agriculture in Serbia, according to the Census of Agriculture (2012), these farms constitute the majority of the total structure. Also, inadequate educational structure is one of the important limiting factors in the application of new technologies in Serbia. The application of IT in Serbian agriculture is at a low level, compared to highly developed countries. As the strategic goal of Serbia is the EU accession, the aim of this research is set in two ways. First, it is necessary to determine the position of Serbia in relation to the EU countries in terms of the dimensions of sustainable development of agriculture. Second, it is necessary to consider all the benefits of using IT in agriculture to the sustainability of this sector.

\section{Material and methods}

The units of observation in this research are Serbia and all countries of the European Union. In order to determine the position of Serbia in relation to the EU countries, in terms of the sustainability of agriculture, a multivariate statistical analysis was used, or Cluster analysis. The database is complemented by available data sources: FAOstat and EUROSTAT. The observation period is from 2009 to 2015. The selected sustainability indicators are:

- Average economic farm size (standard output per farm) as one of the key economic indicators of agriculture in one country;

- Use of inputs: fertilizers, pesticides and diesel fuels - factors that determine the degree of intensification of agricultural 
production (economic, but also environmental impact);

- The resource structure of agriculture - the ratio of agricultural land per active farmer, whereby the resource structure determines the choice of production technology (mechanical and bio-chemical) and the level of partial productivity;

- Share of managers in agricultural holdings without formal education (\%) sociological factor in the application of new technologies;

- Share of organic production area in total agricultural land (\%);

- Share of agriculture in the total greenhouse gas emissions (\%).

The choice of sustainability indicators depends primarily on the available data. The problem is precisely in incomplete databases, especially for agriculture in Serbia. Cluster analysis involves grouping observation units into classes, in such a way that similar units are found in the same cluster (Kaufman \& Rousseeuw, 2009). The paper uses a hierarchical method, the result of which is the Dendrogram, which represents a graphic representation of the cluster in the form of a connecting tree. An important segment of the cluster analysis is the selection of methods for calculating the distance between clusters. In this paper, complete linkage was used, that is, the maximum distance of objects. This method was applied in order to determine the position of Serbia in relation to EU countries.

\section{Results}

Sustainability of agriculture is the adaptation of conventional production, i.e. the use of more efficient technologies, which will reduce or eliminate undesirable effects, primarily on the environment. Hence, without the proper application of all the determinants, the concept of sustainable agriculture remains only a targeted condition that should be achieved. It is also difficult to define this concept precisely, since it implies economic, sociological and ecological sustainability of agriculture. The cluster analysis shows the separation of highly developed EU countries: Germany, France, the Netherlands,

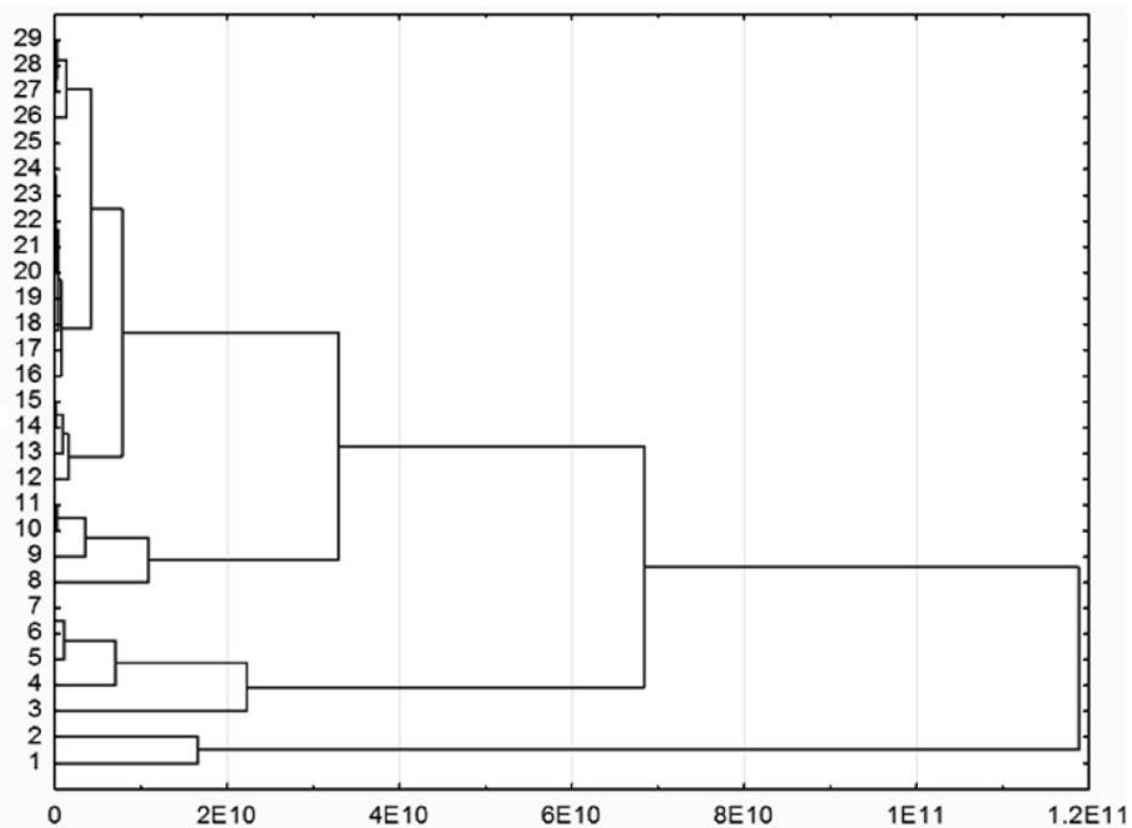

\begin{tabular}{|l|l|l|l|l|l|}
\hline 1- Germany & 6-Czech Republic & 11- Italy & 16- Estonia & 21-Croatia & 26- Slovakia \\
\hline 2- France & 7- Belgium & 12-Romania & 17- Malta & 22- Portugal & 27- Sweden \\
\hline 3- Netherlands & 8- UK & 13- Ireland & 18- Latvia & 23- Lithuania & 28- Finland \\
\hline 4- Luxembourg & 9- Poland & 14- Hungary & 19- Republic of Cyprus & 24- Serbia & 29-Austria \\
\hline 5- Denmark & 10- Spain & 15- Greece & 20- Slovenia & 25- Bulgaria & \\
\hline
\end{tabular}

Figure 1: Cluster analysis

Source: Authors' calculation based on selected indicators 
Luxembourg, Denmark, the Czech Republic and Belgium. Farms in these countries are primarily economically viable given that the average economic size of the holding (measured by total farm income) in these countries is the highest. On the other hand, Serbia is most similar to Bulgaria and Lithuania. In other words, it is notable that the grouping of the socialist countries and the Mediterranean countries (Portugal, Spain, Greece and Italy) is clustered (Figure 1). From the aspect of the average economic size of the holding, in the observed period, Romania, Bulgaria, Serbia and Lithuania have the lowest values. Also, the difference between these countries is reflected in the educational structure of managers of agricultural holdings. The educational structure is an essential basis for the adoption and application of new technologies. Considering the share of managers without formal education, the unfavorable educational structure is a feature of Romania, Bulgaria, Greece and Serbia.

Ecological sustainability of agriculture is reflected in more efficient resource management, that is, through more efficient use of, primarily, chemical inputs. The degree of intensification in this research was observed through the use of pesticides, fertilizers and diesel fuels. It is noticeable that highly developed countries have a higher degree of intensification of agricultural production, which has a negative effect on the environment. However, these countries are the initiators of the implementation of new technologies, in order to maintain an adequate level of productivity to ensure the economic efficiency of the producers, but also to reduce the harmful effects on the environment.

As environmental indicators of agriculture, two variables have been selected: the share of organic production in total agricultural land (\%) and the share of agriculture in total emission with greenhouse effect (\%). As a specific group of countries, Austria, Sweden and Finland stand out. Namely, the agriculture of Sweden and Finland is characterized by a lower degree of intensification of agriculture. From all the analyzed countries, Austria stands out as the country with the largest share of organic production in total agricultural land (around 16\%). Organic agriculture is often classified as an adequate model of sustainable agriculture (OECD, 2003) in research. Serbia has a small share of organic production, given the good resource conditions, which makes it the last country in the countries analyzed in the research, with $0.3 \%$ of the land that makes organic production. It is indisputable that this production, which does not use chemical inputs, provides multiple benefits to the society as a whole. Organic farming contributes to socio-economic and environmentally sustainable development, especially in underdeveloped countries, owing to the application of organic principles, implying efficient local resource management, and thus cost efficiency (Birovljev \& Ćetković, 2014). In other words, organic production can contribute to increase of revenues and improving the quality of life. Agricultural production affects the emission of $\mathrm{CO}_{2}$, methane, nitrogen-sub oxide, which cause a greenhouse effect. Therefore, the European Union has defined measures and directives that affect the reduction of greenhouse gas emissions from the agricultural sector.

\section{The influence of information technology on agricultural sustainability}

All innovations are created with the idea of helping the development of the current. Hence, innovations in the field of information technologies, which are implemented in the context of agricultural production, influence the growth of the quality of the production process, but also the output itself, with lower costs per unit of production, while the effects produced in this way should not affect the disturbance ecosystem. With the application of precision agriculture methods, where the task was to find the best solution for more efficient production, there was considerable savings. Savings are generated in the higher yield of primary culture, reducing the costs of protecting plants and fertilizers. As the basic method of precision agriculture, in this case, satellite positioning and automatic control was used (Zhang, Wang, \& Wang, 2002). From an economic point of view, the producer is always striving to achieve high productivity, high yields and profits. The social character of sustainability by the implementation of information technologies primarily refers to the improvement of the social status of the population in rural areas, as well as through the production of health-safe food, the quality of which meets all standards. Ecological effects of sustainability should affect the reduction of adverse effects on the ecosystem resulting from agricultural production, which ultimately ensures a cleaner environment, thus fully responding to the concept of sustainable agriculture. 
In the series of significant breakthroughs in information technology in agriculture in the last few decades, in particular, GPS technology, or satellite guidance of agricultural machines, is distinguished. It is, undoubtedly, the most advanced technology that is rapidly developing and improving (Luecke \& Katz, 2003). The precursor of precision agriculture is based on a large number of information necessary for decision making. Indirect comparison of the longterm parameters obtained from the plot enables the optimum use of the means of operation, minimizing environmental risks, increasing the quality of products and above all the increase in the profitability of production or profits. This way of agricultural production enables production on the principles of sustainable agriculture. Another innovation in the field of IT in agriculture would be applications (e-mail, weather reports, market prices, etc.) (Gorla, 2009). Digital geographic data that can be stored, analyzed and displayed in a number of different representations are the core of precise agriculture. Systems for handling these data are called GIS. Agriculture is an excellent area for the application of GIS because it represents a natural resource, requires movement, distribution of large quantities of products, goods and services. GIS enables the creation of various forms of reports - from thematic maps and 3D terrain models through multimedia displays to classic tabular reports. Depending on the specific needs, it is possible to create the following thematic maps for a region: the boundaries and division of the general plan area, planned land use, planned water supply systems, planned system of channelling atmospheric and wastewater, planned watercourse management (Čekerevac, Anđelić, Glumac \& Dragović, 2010).

Milovanović (2014) in his research points to the difference in the application of information technologies in the EU countries. Namely, in countries such as Bulgaria and Romania, there is a lower level of use of new technologies compared to highly developed EU countries. The analyzed technologies are:

- Use of computers;

- Internet;

- Use of mobile phones;

- Farm Informational System;

- Livestock registration;

- Geo-fertilizing.

Namely, as agriculture is characterized by predominantly small, traditional farms, unfavorable educational as well as age structure, it has the problem of implementing IT technologies. Potential difficulties when the implementation of these methods in agricultural production of Serbia is possible are also evident in the face of poor financial situation of the population, which mostly deals with the traditional type of production, or the inability to invest in the modernization of agricultural production. Observing only the use of the two most basic IT: computers and the Internet, according to the Census of Agriculture (2012) in Serbia, less than $2 \%$ of the total number of households use a computer. Also, according to the World Bank (2018), the availability of the Internet in Serbia (next to Romania and Bulgaria) amounts to less than $50 \%$ of the total population. In highly developed countries, such as the Netherlands, Denmark, Sweden, Luxembourg, more than $90 \%$ of the total population has access to the Internet.

\section{Conclusion}

The long-term sustainable development of agriculture implies sustained economic growth, technological advancement, efficient resource management and increasing quality of life in the final instance. Observing the position of Serbia in relation to EU countries, Serbia's agriculture is lagging behind in other countries. In practice, sustainability of agriculture is achieved through the coordination of the activities of agrarian and environmental policy. The importance of sustainability within the European Union has already been highlighted, defining laws and directives aimed at protecting the agroenvironment and increasing the standard of living of farmers. On the other hand, compared to European Union countries, Serbia's agricultural performance is significantly lagging behind. The imperative of agricultural policy in Serbia in the future period is harmonization with the principles of the Common Agricultural Policy of the EU, as well as harmonization of the environmental protection policy with the EU rules. The chance for agriculture in Serbia is represented by IPA funds, that is, IPARD component of pre-accession assistance to candidate countries for EU membership, aimed at reducing developmental disparities. Modern agriculture becomes the area of information technology use. The development of agriculture and the provision of health-safe food are common concerns of the international community. The positive impact of IT on the sustainability of agriculture is indisputable. The future goals of Serbia's agriculture development 
should include modernization and increasing the competitiveness of agricultural producers. Considering the technological lag of Serbia's agriculture, these goals cannot be achieved in the short term.

\section{References}

Birovljev, J. \& Ćetković, B. (2014). The Role of Organic Production and Permaculture in Ensuring Economic Efficiency of Agroeconomy of Serbia. Strategic Management, 19(2), 27-32

Census of Agriculture (2012). Database. Retrieved 25.09.2018. from http://popispoljoprivrede.stat.rs/

Čekerevac, Z., Anđelić, S., Glumac, S. \& Dragović, G. (2010). Modern trends apply GIS technologies. International Scientific Conference Management, Kragujevac.

Ćelić, Đ., Drašković, Z., Uzelac, Z., \& Petrov, V. (2018). Differences in attitudes toward internet usage: Empirical study from Serbia. Strategic Management, 23(3), 17-24. https://doi.org/10.5937/StraMan1803017C

EUROSTAT (2018). Database. Retrieved 25 September 2018. from http://ec.europa.eu/eurostat

FACET (Fostering Agriculture Competitiveness Employing Information Communication technologies) (2013). Using ICT to Enhance Marketing for Small Agricultural Producers. USAID.

FAOstat (2018). Database. Retrieved 25 September 2018 from http://ec.europa.eu/eurostat

Franklyn, C., \& Tukur, A. (2012). Problems and prospects of adopting ICT in agriculture: some comments. African journal of agricultural research and development, 5(3), 39-47.

Gorla, N. (2009). A Survey of Rural e-Government Projects in India: Status and Benefits. Information Technology for Development, 15(1), 52-58. https://doi.org/10.1002/itdj.20064

\section{$\bowtie$ Correspondence}

\section{Bojan Matkovski}

Faculty of Economics in Subotica

University of Novi Sad

Segedinski put 9-11, 24000, Subotica, Serbia

E-mail: bojan.matkovski@ef.uns.ac.rs
Kaufman, L., \& Rousseeuw, P. J. (2009). Finding groups in data: an introduction to cluster analysis (Vol. 344). John Wiley \& Sons.

Legg, W., \& Viatte, G. (2001). Farming systems for sustainable agriculture. Organisation for Economic Cooperation and Development. The OECD Observer, (226/227), 21.

Luecke, R., \& Katz, R. (2003). Harvard business essentials: managing creativity and innovation. Brighton: Harvard Business School Press.

Milovanović, S. (2014). The role and potential of information technology in the improvement of agriculture. Economics of Agriculture, 61(2), 471-485.

OECD (2003). Organic Agriculture: Sustainability, Markets and Policies. Wallingford: CABI Publishing. https://doi.org/10.1787/9789264101517-en

The United Nations Coference on Enviroment and Development/ UNCED (1992). Rio Declaration on Enviroment and Development. Rio de Janeiro

The World Bank (2018). Database. Retrieved 25 September 2018 from http://ec.europa.eu/eurostat

Tilman, D., Fargione, J., Wolff, B., D'antonio, C., Dobson, A., Howarth, R., ... \& Swackhamer, D. (2001). Forecasting agriculturally driven global environmental change. Science, 292(5515), 281-284.

Verdouw, C. N., Beulens, A. J., Trienekens, J. H., \& Verwaart, T. (2010). Mastering demand and supply uncertainty with combined product and process configuration. International Journal of Computer Integrated Manufacturing, 23(6), 515-528 https://doi.org/10.1080/09511921003667706

Zhang, N., Wang, M., \& Wang, N. (2002). Precision agriculture - a worldwide overview. Computers and Electronics in Agriculture, 36(2-3), 113-132. https://doi.org/10.1016/S0168-1699(02)00096-0 